\title{
A TRADUÇÃO E SUA RELAÇÃO COM O INCONSCIENTE: TRANSMITIR A PSICANÁLISE
}

\author{
Viviane Veras
}

$\mathrm{Eu}$ lhes soletrei, ponto por ponto, o funcionamento do que nos foi produzido primeiro por Freud como fenômeno do inconsciente. No sonho, no ato falho, no chiste - o que é que chama atenção primeiro? É o modo de tropeço pelo qual eles aparecem.

(Lacan, O seminário - livro 11)

L'une-bévue é uma forma tão boa como outra qualquer de traduzir l'Unbewusst (inconsciente): o inconsciente em particular, que em francês, e em alemão também, aliás, equivoca com a inconsciência, então por que não traduzir tranquilamente por l'une-bévue, ainda mais que essa tradução tem a vantagem imediata de por em evidência certas coisas [...] Este ano, com esse insabido que sabe de l'une-bévue, tento introduzir alguma coisa que vá mais longe que o inconsciente.

(Lacan, L'insu que sait de l'une-bévue s'aile à mourre)

O título deste trabalho faz eco ao texto freudiano $O$ chiste e sua relação com o inconsciente (1905), a que me dediquei em minha tese de doutorado (1999), e cuja alquimia verbal me obrigou a lidar com esses exercícios de passagem entre línguas que podemos chamar de traduções. A escrita dessa tese, além das dificuldades que normalmente enfrentamos na lida com esse tipo de texto, revelou de saída uma dificuldade: a necessidade, imposta por Freud, de incluir no chiste - o chamado objeto de estudo - o sujeito, desalojado pelo riso do lugar do observador externo, e mesmo do lugar do observador participante ${ }^{1}$. Estranhamente, a própria impossibilidade de circunscrição desse objeto é que vai garantir seu modo de ser equívoco, entre o tropeço e a trapaça.

Como não leio alemão, o Freud que leio é sempre um Freud traduzido, e uma de minhas dúvidas, talvez a maior enquanto trabalhava com o livro dos chistes, era saber

\footnotetext{
${ }^{1}$ Nas pesquisas etnográficas, por exemplo, conta-se com uma interação do pesquisador com o pesquisado e com a distância que permite que, mesmo dentro, ele permaneça fora.
} 
se era possível lidar com a escrita de Freud a partir de traduções — questão que foi se instalando aos poucos, alimentada pelos próprios comentários de consagrados tradutores de Freud. Para começar, as notas de James Strachey, o tradutor inglês (a quem também se remetem outros tradutores ${ }^{2}$, retomando notas, acrescentando outras), que faz questão de esclarecer — frente à barreira imposta pela literalidade do chiste, inseparável da língua em que se faz - que o alvo de sua tradução é o presumido verdadeiro conteúdo da teoria freudiana, e não o estilo, os floreados, os ornamentos que poderiam turvar o brilho dessa verdade. Para o tradutor, a coleção de chistes é algo em que Freud "baseia sua teoria", e observa que o "próprio" Freud refere-se ao livro com um tom depreciativo, que essa é a obra freudiana menos lida... para culminar com o comentário de ela ser também a que traz mais problemas para o tradutor. E é com o conhecido chiste italiano traduttore - traditore! que previne o leitor não alemão e anuncia a "estranha fatalidade" do desaparecimento do chiste na sua passagem para a explicação no rodapé. É interessante observar todo o cuidado do tradutor em apontar diversas dificuldades, que já começam com o título da obra (Der Witz...), para acrescentar, encerrando seu prefácio, que são "dificuldades superficiais" para um leitor que tem em vista "mais que um momento de diversão". Eis, então, o riso calado ${ }^{3}$.

O problema é que o chiste se traveste justamente nesse modo de se dizer sem se dizer, em sua forma esquiva de dar passagem ao desejo, manifesto no que Freud chamou de uma "vestimenta chistosa" sob a qual não adianta buscar a verdade nua e crua. O chiste se dá a ler como ruptura, interrupção, como uma descontinuidade, uma vacilação (Lacan, 1998c: 30) na relação da língua com ela mesma, com o sistema, para lembrar Saussure, que tem sua “ordem própria” (1972: 31) abalada pelo corpo

\footnotetext{
${ }^{2}$ Acompanhei as traduções para o português [de Vera Ribeiro para a Imago, 1989], para o francês [Denis Messier para a Gallimard, 1988], o inglês [tradução de James Strachey para a Hogarth Press, 1960] e para o espanhol, de José L Etcheverry, para a Amorrortu. Todas as citações do livro dos chistes são traduzidas por mim a partir da Amorrortu.

${ }^{3}$ Nesse prefácio ao livro dos chistes, Strachey apresenta suas pesquisas sobre as dificuldades com as traduções de termos como Witz, joke, wit, Scherz, jest, Komic, comic, Humour, humour. Lembro que Freud faz um trabalho de pesquisa semelhante no texto "O estranho" ("Das Unheimliche"), em que recorre à tradução para tentar iluminar o estranhamento do termo alemão. Para esse texto, o tradutor aparentemente contraria a posição tomada no prefácio aos chistes, e seu alerta é outro: "A primeira seção do presente artigo, com a sua extensa citação de um dicionário alemão, apresenta especiais dificuldades para o tradutor. Espera-se que os leitores não se deixem desencorajar por esse obstáculo preliminar", mas o que vale mesmo é o que oferece como motivação para continuar a leitura: "pois o artigo está cheio de material importante e interessante e vai muito além dos tópicos simplesmente linguísticos" (1995 [1919], p. 284, grifos meus). Mais uma vez, o que importa está além do superficial e do obstáculo linguístico.
} 
estranho, impróprio, que poderia ser excretado pelo riso, pelo rubor, pela dor, ou, mais além do corpo, pela fixação do que dele restou em uma tipologia. Na tradução para outra língua é possível reproduzir esse abalo produzido por uma alteridade que habita a língua em que ele se deu? Que tipo de equívoco pode ressoar numa tradução entre uma língua e outra?

No livro dos chistes, temos um Freud que se faz autor, objeto de análise, intérprete e leitor; um Freud que apreende, ao mesmo tempo, que sua teoria se descobre (comprovando mecanismos já apontados no livro dos sonhos, em 1900) e se reinventa nesse outro objeto de estudo, no caráter paradoxal dessa formação do inconsciente ${ }^{4}$, cuja chave de interpretação não se oferece a partir do já escrito, do já conhecido, uma vez que obedece a outras leis - leis que impõem também à teorização freudiana um ritmo, uma intermitência.

No capítulo dedicado ao estudo da técnica, Freud insiste nas formações literais do chiste, decifrando-as como o que chamou de rébus, "charadas de cabeça pra baixo" (1989: 32, nota 22): no rébus, a técnica é dada e o texto se oculta; no chiste, a técnica precisa ser adivinhada, mas o texto é dado. Um exemplo simples, atribuído a Voltaire ${ }^{5}$ (Costello, 1988: 8), pode servir aqui para mostrar como o trabalho de leitura, interpretação e tradução envolvem o próprio sistema simbólico da língua. Frederico II da Prússia, grande amigo de Voltaire, envia-lhe um bilhete em que está escrito 6 heures sous $P$ à 100 sous 6 , que, lido em francês, soa como Six heures souper à Sans Soucis. A resposta de Voltaire resume-se a "G a", que pode ser lido como G grand a petit - na literalidade do francês, a frase se impõe por si: J'ai grand appétit. Esses rébus, descobertos na linguagem figurativa dos sonhos, constituem para Freud a melhor prova de que, nesses casos, não se trata de sentido, mas de um deciframento se traduzirmos para o português: "6 horas sob P em 100 sob 6" / "Seis horas, cear em Sans Soucis" e "Ge grande a pequeno" / "Tenho grande apetite", perdemos o valor literal em que se oculta o texto em língua francesa, uma vez que a letra não é traduzível.

\footnotetext{
${ }^{4}$ Foi Lacan quem reuniu sonhos, sintomas, chistes, lapsos e atos falhos sob o nome "formações do inconsciente", que é também o título do seminário de número 5 (1957/1958, 1999).

${ }^{5}$ Encontrei esse rébus no livro de Costello (ver referências), mas há inúmeras referências eletrônicas, mais detalhadas e explorando o lado figurativo da charada. Uma delas traz uma equação do encontro marcado: $\quad$ a 6 heures $\frac{P}{A}$ a $\frac{6}{100}$, e sua resposta é remetida a uma obra de Geoffroy Tory, de 1529. Disp. em http://j.poitou.free.fr/pro/html/lud/rebus.html Acesso em setembro de 2009.
} 
Admitamos que a charada, feita para ocultar um texto em francês, não poderia ser lida de forma alguma em outra língua e, portanto, não poderia ser traduzida. No caso do chiste, como o texto se mostra (a vestimenta chistosa), a tradução deveria ser sempre possível, mas a dificuldade continua, porque a técnica pode servir de barreira. Vejamos, então, um exemplo de Artemidoro, citado por Freud no livro dos sonhos (1989: 135): Alexandre da Macedônia e seu exército mantêm Tiro sitiada, mas ele hesita em atacar a cidade. Tem então um sonho, no qual um sátiro dança sobre seu escudo. Aristandro, o intérprete que acompanhava seu exército, lê o sonho do rei tomando a palavra grega Satyros em dois fragmentos: Sa e Tyro, interpretando-os como "Tiro é tua", e aconselhando a invasão da qual Alexandre sai vitorioso. Aristandro não se deixa levar pela imagem do sátiro dançando sobre o escudo, e toma o relato em sua literalidade, e é nessa literalidade que Freud vai descobrir o funcionamento de outra cena, outra sintaxe, outra forma de estruturação em que Lacan (1998a: 271) vai reconhecer o testemunho do descobridor do inconsciente, nos confins da fineza do chiste, cujo brilho secreto Freud faz cintilar.

Está aí, nessa literalidade - na qual vai esbarrar a tradução —, o que Freud chama de algo como uma benevolência do chiste: "as palavras são um material plástico, com o qual se pode fazer todo tipo de coisas [...] e a técnica do chiste pode aproveitar tais constelações de material lingüístico" (1989: 35). Freud insiste nessa resiliência do material verbal, esvaziado de significação, puro jogo de palavras, e é com precisão de flecha que aponta nesses ajuntamentos de letras o que chamou de Witz $^{6}$. Freud localiza neles um saber "insabido" que vai soletrar, decifrando seus elementos literais.

No meu trabalho, não precisei ir muito longe para descobrir que os chistes alemães resistiam tanto à explicação — de que se vale inicialmente Freud para tentar descondensar a formação chistosa com uma espécie de tradução intralingual (dizendo-o com outras palavras, ávidas do sentido que a irreverência do chiste recusa) - quanto à tradução para outras línguas: ambas lhes tiram a graça. E a dificuldade de definição dessa equivocação torna-se ainda mais sutil, porque, dependendo das circunstâncias, o jogo pode ainda resultar num lapso, que envergonha e faz de quem "falou" um objeto de

\footnotetext{
${ }^{6}$ Seligmann-Silva esclarece em nota (1999: 135) que a tradução do Witz alemão por "chiste", "jogo de palavras" ou "tirada espirituosa" vai indicar apenas a perspicácia, a espirituosidade, mas não a arte combinatória - síntese química, achado, idéia que irrompe, segundo Benjamin (id., p. 56). Importa notar que é também nessa arte, marca dos filósofos alemães da era romântica, que tanto Freud quanto Lacan estão interessados, mas não só nela, porque Freud considera os chistes que jogam com o som, os Klangwitze, que eram desprezados pelos intelectuais de sua época.
} 
riso. Para fazer rir, como diz Bergson (1980), para que haja esse tipo de transmissão que produz o riso, é preciso ser da paróquia, ao mesmo tempo hóspede e refém desses oikos.

O chiste se faz reconhecer apenas quando já nos subornou a escuta, submetendonos, naquele instante preciso, a seu controle - o controle de nosso corpo que ri. $\mathrm{O}$ equívoco que terá desatado o riso pode se fixar na língua como um neologismo, por exemplo, passível de uma classificação tipológica, mas, para que volte a subornar (bestochen), precisa ser contado de novo, encenado, para que isso, digamos assim, se transmita. Quem conta, assim como quem traduz, tem que situar, contextualizar o relato, refazer suas condições de enunciação, uma vez que ele não tem autor, tem agentes, e sua marca é a resistência à tradução.

Foi ciente de todas essas dificuldades que fui pouco a pouco aceitando o desafio de traduzir textos psicanalíticos que abordam os trabalhos de Freud e de Lacan. Enquanto trabalhava com o livro dos chistes, o que me intrigava era sempre a mesma questão levantada no prefácio pelo tradutor James Strachey: sobrevalorizar os elementos da escrita como ritmos, sonoridades, variações de perspectivas, escolhas lexicais, arranjos sintáticos e correr o risco da traição ao conteúdo das idéias; correr o risco de fazer falhar a transmissão da psicanálise. Contudo, no caso específico dos chistes, eram justamente essas singularidades, aparentemente insignificantes, que se tornavam objeto do zelo do tradutor, e exigiam que ele saísse da linha - ao menos fez com que os tradutores (como o tradutor Etcheverry (1989), que escreveu um volume inteiro sobre a tradução castelhana) justificassem cada opção, e deixassem nos rodapés as pegadas que permitem hoje uma leitura crítica dessa feitiçaria verbal, daquilo que precisaram calar dizendo e do que disseram calando.

Neste trabalho, interessa-me discutir, mais especificamente, a questão dessa transmissão. Para abordá-la de modo mais direto, ponho em diálogo uma conferência de Jacques Lacan, realizada em outubro de 1975, e o albergue do longínquo de Antoine Berman, de 1985, na tentativa de apontar uma relação entre tradução e inconsciente a partir da experiência e do compromisso, da submissão e da língua materna.

$\mathrm{Na}$ chamada "Conferência em Genebra sobre o sintoma", Lacan começa falando de sua necessidade de salvaguardar o legado freudiano; necessidade que o havia levado tanto a ensinar quanto a reunir em um livro, em 1966, seus Escritos - sem

\footnotetext{
${ }^{7}$ As citações desse texto, e de outros que não trazem o nome do tradutor nas referências, são traduções minhas.
} 
deixar de chamar a atenção para o fato de que "escrever não é de forma alguma o mesmo que dizer", e que "a psicanálise é muito diferente dos escritos". Em todo caso, era preciso que algo restasse do que falava nos seminários; algo destinado à leitura (de legere — ler, recolher) e ao legado (de legare - o que legitima e estabelece um contrato: não se pode ler sem compromisso).

A despeito do estranhamento que o título da obra pudesse causar, com seus Escritos Lacan comenta na conferência que "queria assinalar que isso era de algum modo o resíduo de meu ensino". Esses escritos (publicados ano a ano na revista La Psychanalyse) pretendiam "conservar algo do rebuliço que minha fala havia engendrado, destinados a conservar dela um apetrecho ao qual poderiam reportar-se..." Não é de estranhar, portanto, que afirme no Seminário 5 - As formações do inconsciente (1999 [1957-1958]), que parece que para alguns é seu estilo que barra a entrada do artigo em cuja leitura insiste: "A instância da letra no inconsciente ou a razão desde Freud", e encerra o assunto dizendo: "Lamento, não há nada que eu possa fazer — meu estilo é o que é... e há também, nas dificuldades desse estilo... algo que corresponde ao próprio objeto que está em questão" (1999: 33).

$\mathrm{Na}$ conferência que percorro aqui, quase 20 anos depois desse seminário, Lacan ainda fala da necessidade de dar certo testemunho do que o psicanalista faz, de pensar no que faz como analista, "ele é livre, pode não fazê-lo e ficar com as coisas para si, mas é livre também para se oferecer a essa prova de ir confiar, confiar coisas às pessoas...". A que pessoas?, pergunta-se. Àquelas que já são experientes? Mas a experiência é que vai justamente fazer com que uma análise seja lembrada em relação a outra, contrariando a proposta freudiana de não encaixar um caso antecipadamente numa categoria. $\mathrm{O}$ que é muito difícil, porque, se já se tem a experiência, não é possível jogá-la fora. O que fazer com ela? De que experiência é preciso valer-se? Como transmitir a experiência da análise se não nos submetemos a ela? Se não nos deixamos subornar?

Em A tradução e a letra ou o albergue do longínquo, depois de afirmar a estreita relação entre tradução e filosofia, Berman fala justamente de dois campos de experiência em que se elabora hoje em dia (1985) uma reflexão múltipla sobre a tradução; campos de experiência em que se reafirma a relação fundamental entre a tradução e a letra: o da tradução bíblica, e o campo (a que me atenho neste trabalho) que Berman descreveu como "experiência sempre mais decisiva que a psicanálise faz da tradução (do destino da tradução) dos seus textos fundadores", destacando que a 
interrogação da psicanálise sobre a tradução permanece atrelada à experiência da própria psicanálise com a tradução (p. 20-21). Foi a essa experiência atrelada que me referi especificamente ao que acontece no trabalho com os chistes, em que o tradutor se vê obrigado a explicar um chiste na sua língua de tradução, um chiste que é já um estranho familiar na língua alemã, que ele habita de forma inédita. Maria Rita Moraes, em trabalho apresentado no $2^{\circ}$ Encontro Mundial dos Estados Gerais de Psicanálise, conta que, em 1908, Freud escrevia a Jung: "Infelizmente a Traumdeutung é intraduzível, e precisaria ser novamente refeita em cada língua"... Esse intraduzível dos sonhos e dos chistes diz respeito à tradução que bate de frente com o significante, com o modo como isso ressoa, e que Jacques Derrida (1996) chama de o intraduzível corpo das línguas.

Mas, vamos adiante. Vamos ao momento em que Berman fala que a forma de ensinamento que propõe para a tradução seja a da psicanálise, e justifica afirmando que todo tradutor está sob um jogo de forças deformadoras sancionado cultural e literariamente. Quem leu o livro pode objetar que Berman não fala aqui de inconsciente, mas de tradução etnocêntrica e hipertextual, mas quero destacar, entremeado aos tipos de tradução, o jogo de forças deformadoras que vai reaparecer 20 páginas adiante e, de forma muito especial para este trabalho, no último parágrafo do livro de Berman.

Essas forças fazem parte do ser-tradutor daquele que traduz, e determinam, $a$ priori, seu desejo de traduzir, eis o que diz o autor. E fala, então, de uma necessidade de análise desse "sistema de deformação": parte por parte, no sentido cartesiano, "mas também no sentido psicanalítico, na medida em que esse sistema é grandemente inconsciente e se apresenta como um leque de tendências, de forças que desviam a tradução de seu verdadeiro objetivo" (2007: 44) (deixo em reserva esse "verdadeiro objetivo", para defender, mais adiante, a necessidade do desvio e da deformação como reveladores de uma verdade — "Há que apenas saber errar bem o seu idioma", como diz Manoel de Barros no poema "Mundo pequeno", em O livro das Ignorãças, 1993: 87).

A relação com o inconsciente está engatada, afinal. Ela está afirmada também na conferência de Lacan, que mostra, a partir de exemplos e de sua crítica afiada ao Vocabulário de Psicanálise dirigido por Daniel Lagache (que à la gâché - desperdiçou toda a psicanálise), a importância vital de os analistas se familiarizarem com as questões levantadas pela tradução, mostrando como é possível alterar a concepção teórica e clínica de Freud a partir de escolhas que não considerem a gramática, a sintaxe, o 
léxico, a retórica de sua língua alemã. Sem falar na crítica de Lacan às próprias escolhas de Freud, especialmente aquela que dá nome à hipótese do inconsciente - que caracteriza como uma hipótese mal nomeada, porque o inconsciente não é somente o não sabido. Lacan translitera, para o francês l'une-bévue, o inconsciente Unbewusst freudiano - no seminário L'insu qui sait de l'une-bévue s'aile a mourre (1976-1977), afirma: "O que se diz a partir do inconsciente participa do equívoco (bévue), que é o princípio do chiste - equivalência do som e do sentido".

É desse não sabido freudiano que está falando Berman quando diz que o fato de o tradutor tomar consciência dessas forças desviantes da tradução não basta para eliminá-las, apenas uma "análise" (a palavra vem envolta nas aspas da precaução) de sua atividade permite (o verbo está no presente, não há aí um “permitiria”) neutralizálas - mas o autor junta aí uma nota que leio agora: nota 16: neutralização relativa, uma vez que Freud, numa carta a Fliess a respeito das "psiconeuroses", chamava de "defeito de tradução", o que lhe parecia constitutivo do traduzir. O espaço da tradução é aquele da inevitável fragilidade. O defeito da tradução é inerente à tradução. Por que esse defeito? Qual o seu fundamento? Para responder a essas perguntas, é preciso provavelmente uma analítica do sujeito que traduz, o "tradutor" (2007: 133).

Berman reconhece o defeito inerente, embora mantenha o verdadeiro objetivo da tradução e a impossibilidade de eliminá-lo, ao mesmo tempo em que observa que somente submetendo-se a "controles" (no sentido psicanalítico - além das aspas / em alemão é a forma latina Kontrolle) os tradutores podem esperar libertar-se parcialmente desse sistema de deformação, marcado na estrutura etnocêntrica como "língua culta". E essas línguas cultas, que são as que traduzem, são as que mais resistem, são as que censuram. Nesse momento, o autor faz algo como um voto: "imagina-se tudo o que uma psicanálise voltada para a língua pode trazer para a tradutologia”, e atribui aos analistas a abordagem psicanalítica da tradução, "desde que façam da experiência da tradução uma dimensão essencial da própria psicanálise" (p. 44-45, grifo meu). Nesse ponto, outra nota que convém destacar: a nota 17 , que diz que a lista dos textos analíticos sobre a tradução não para de aumentar e constitui um corpus fundamental (2007: 133).

Vamos atentar para o "desde que" de Berman: fazer da experiência da tradução uma dimensão (lendo lacanianamente, uma diz-mansão) essencial da própria psicanálise. Na conferência em Genebra, Lacan diz que os pais modelam o sujeito na função do simbolismo pela forma como instilam no bebê um modo de falar que porta a marca de como os pais o aceitaram. A linguagem de que fala Lacan não tem existência 
teórica, e intervém sempre sob a forma do que ele chama de lalação. Assim, a língua constitui de alguma forma algo como um patrimônio, e segundo o modo como ela foi falada e também ouvida - endereçada a cada um em sua singularidade. O estilo tem a ver com isso, com os detritos que a água da linguagem deixa passar pela peneira, escorredor (um passador, passoire) e com os quais a criança brinca, para depois desembaraçar-se deles como puder.

Como o poeta Manoel de Barros (1999: 8) transforma essa lalação — a lalangue de Lacan - em energia "domensticada" (traduzindo um neologismo de Lacan)... e pode encontrar veredas de criação:

Tenho um livro sobre águas e meninos.

Gostei mais de um menino que carregava água na peneira.

(...)

Com o tempo descobriu que escrever seria o mesmo que carregar água na peneira.

Com a criança e o poeta chegamos ao final da conferência e aos confins do albergue de Berman - ambos terminam mesmo falando de Joyce. Lacan declara que Joyce havia tentado situar o ser humano de um modo sem precedentes, e nisso o que mais atrai Lacan é a dimensão humana.

Chegamos ao último capítulo do livro de Berman: "O coração aberto da língua", que tem início com o enunciado: "Aborda-se a difícil questão da relação da tradução com a língua materna”. O tradutor que surge no final do livro de Berman trabalha no que a língua tem de mais materno, no que tem de não-normatizado. E pressente a língua materna como algo que não se confunde com a visão tradicional, de base histórica, também dita língua nacional, como uma realidade fechada. E declara que a língua materna é "um espaço-de-língua aberto e fundamentalmente acolhedor" (p. 131), em que o tradutor descobre o parentesco não filológico, não lingüístico das línguas. Nesse coração, todas as línguas são próximas e parentes, tal como diz o Freud das Afasias, (citado por Maria Rita Moraes, 2003), língua materna e línguas estrangeiras ficam no mesmo campo simbólico, numa espécie de reserva indígena, como diz Lacan (1998 [1964]).

A tradução, considerando as forças deformadoras do inconsciente e sua transgressão libertadora, não se desvia, portanto, de seu verdadeiro objetivo. Ela diz o 
que não pode ser dito pela via do sentido, e se diz pela via da interrupção, do equívoco, fazendo a experiência dos limites.

Pode-se dizer que uma tradução que se impõe pode ser dessubjetivante, e que na passagem de uma língua para outra lalangue se inventa e sofre transformações: condensações e deslocamentos que expõem a resiliência do material lingüístico; formações, como o chiste, capazes de mostrar a inutilidade das ideologias da comunicação - o tradutor joga com as palavras e é jogado por elas, experimenta no corpo o efeito de interpretação próprio à tarefa da tradução.

Uma observação a mais sobre a transmissão: no tempo das urgências atuais, o que se propõe é simplificar. É verdade que a interpretação clara, nítida e explicativa certamente ganharia tempo, economizaria dinheiro e nos desembaraçaria das tramas em que se entremeiam as inquietantes estranhezas, os dramas familiares, as representações inconscientes e seus afetos; livrando-nos também do recalcamento e das resistências. Mas será que os escritos psicanalíticos, com todos os seus desvios, omissões e deformações podem ser dispensados? Uma tradução que se diz fiel à teoria, que deixa em segundo plano a participação subjetiva que Freud mesmo se vê obrigado a reconhecer em suas análises, está sendo fiel a quê? Uma historinha judaica, adaptada da história completa analisada por Žižek (1991), pode nos dar uma resposta a essa questão:

Um polonês e um judeu estão num trem, no mesmo vagão. O polonês senta-se ao lado do judeu. Está inquieto. Minutos depois, não conseguindo mais se conter, pergunta ao judeu:

- Diga-me como é que vocês, judeus, conseguem tirar das pessoas até o último centavo, e assim acumular riqueza?

— Bem, eu lhe direi, mas não a troco de nada.

- Quanto quer?

— Bom, dê-me 5 zlotis.

Em seguida o judeu começa a contar uma história cheia de detalhes:

- Você tem que pegar um peixe morto, cortar-lhe a cabeça, despejar as vísceras em um copo d'água, esperar a lua cheia...

- E aí? Pergunta avidamente o polonês.

- Calma. Isso ainda não é tudo, mas se quiser saber o que vem depois tem que me pagar mais 5 zlotis.

Depois de receber mais uma moeda, o judeu continua, pára, torna a pedir dinheiro... Até que, finalmente, o polonês se enfurece:

- Ah! Que mesquinho! Então é assim que o senhor ganha dinheiro! Não existe segredo nenhum!

O judeu, muito tranqüilo, comenta:

— Pois é! Você compreendeu, então, como é que os judeus... ${ }^{8}$

\footnotetext{
${ }^{8}$ Essa historinha adaptada de Žižek foi também explorada em outro trabalho, "Freud: tramas e traumas de um contador de casos" (Veras, 2006).
} 
Que permaneçam, então, outras perguntas: será que uma resposta imediata do judeu, uma resposta do tipo "não existe segredo nenhum", faria com que o polonês aprendesse melhor essa lição? Será que o saber que aí se transmite dispensaria o suposto saber ${ }^{9}$ que causa o desejo?

É o estilo, tanto o de Freud quanto o de Lacan, quanto o de quem se dispõe a levar adiante o trabalho de transmissão, que exige do tradutor que encene em seu texto, com tato e escuta afinada, com seu estilo, uma nova maneira de fazer-se um tempo para transmitir. Valendo-se dos recursos de outra língua, o tradutor é instado a renunciar voluntariamente - como pressupõe o exercício da psicanálise - a uma posição de saber, e a reconhecer que é impossível traduzir qualquer texto que ponha em jogo o que Lacan (1975) nomeou, na conferência de que estamos falando, motérialisme ${ }^{10}$, sem que efeitos de inconsciente se atravessem nessa passagem e deixem nela suas pegadas.

\section{Referências bibliográficas}

BARROS, Manoel de (1993) O Livro das ignorãças. Rio de Janeiro: Record.

BARROS, Manoel de (1999) Exercícios de ser criança. Bordados de Antônia Zulma et alli. sobre desenhos de Demóstenes Vargas.Rio de Janeiro: Salamandra.

BERGSON, Henri (1980 [1900]) O riso: ensaio sobre a significação do cômico. Trad. de Nathanael C. Caixeiro. Rio de Janeiro: Zahar.

BERMAN, Antoine (2007 [1985]) A tradução e a letra ou o albergue do longínquo. Trad. de Marie-Hélène C. Torres, Mauri Furlan, Andréia Guerini. Rio de Janeiro: 7Letras.

COSTELLO, M. J. (1988) The greatest puzzles of all time. New York: Prentice Hall Press.

DERRIDA, Jacques (2005 [1996]) "Fidelidade a mais de um — merecer herdar onde a genealogia falta". Trad. de Paulo Ottoni. Em Ottoni, P. (2005) Tradução manifesta: double bind e acontecimento. Campinas: Editora da Unicamp / São Paulo: EDUSP.

ETCHEVERRY, J. L. (1989) Sobre la versión castellana. Buenos Aires: Amorrortu.

FREUD, Sigmund (1995 [1919]) "O estranho". Trad. de Eudoro A. M. de Souza. Org. com. e notas de James Strachey com a colaboração de Anna Freud. Em Jaime Salomão (direção geral e revisão) Edição standard das obras psicológicas completas de Sigmund Freud v. 17. Rio de Janeiro: Imago.

(1989 [1905]) El chiste y su relación con lo inconciente. Org. com. e notas de James Strachey com a colaboração de Anna Freud. Trad. direta do alemão de José L Etcheverry. Obras completas: Sigmund Freud v.8. Buenos Aires: Amorrortu.

\footnotetext{
${ }^{9}$ Trata-se de um saber sobre os modos "secretos" de ganhar dinheiro; saber que o polonês supõe que o judeu detém.

${ }^{10}$ Trata-se de um jogo de palavras com a palavra, uma condensação, na terminologia freudiana: mot ("palavra") e matérialisme ("materialismo")
} 
(1989 [1900]) La interpretación de los sueños. Org. com. e notas de James Strachey com a colaboração de Anna Freud. Trad. direta do alemão de José L Etcheverry. Obras completas: Sigmund Freud v.4 e 5. Buenos Aires: Amorrortu. LACAN, J. (2003 [1970]) "Radiofonia" (junho de 1970). Outros escritos. Trad. de Vera Ribeiro. Rio de Janeiro: Jorge Zahar.

(1999 [1957-1958]) O Seminário, livro 5: As formações do inconsciente. Trad. de Vera Ribeiro. Rio de Janeiro: Jorge Zahar.

(1998a [1966]) "Função e campo da fala e da linguagem em psicanálise". Escritos. Trad. de Vera Ribeiro. Rio de Janeiro: Jorge Zahar.

(1998b [1966]) “A instância da letra no inconsciente ou a razão desde Freud”. Escritos. Trad. de Vera Ribeiro. Rio de Janeiro: Jorge Zahar.

(1998c [1964]) O Seminário, livro 11: Os quatro conceitos fundamentais da psicanálise. Trad. de M. D. Magno. Rio de Janeiro: Jorge Zahar.

(1996 [1975]) "Conférence à Genève sur le symptôme" (1975). Bulletin de l'Association freudienne internationale, Paris. inédito.

(1976-1977) L'insu qui sait de l'une-bévue s'aile a mourre. Seminário

MORAES, M. R. S. (2003) "O que (se) passa na Tradução? O que (ultra)passa a Tradução?”. Estados Gerais da Psicanálise: $2^{\circ}$ Encontro Mundial, Rio de Janeiro.(http://www.estadosgerais.org/mundial_rj/download/3f_Moraes_109141 003_port.pdf) Acesso em setembro de 2009.

POITOU, J. "Cryptographie: texte crypté, texte caché". Langages, écritures, typographie. (http://j.poitou.free.fr/pro/index.html) Acesso em setembro de 2009.

SAUSSURE, F. ([1972 [1916]) Curso de linguística geral. Trad. de Antônio Chelini, José Paulo Paes e Izidoro Blikstein. São Paulo: Cultrix.

SELIGMANN-SILVA, Marcio (1999) Ler o livro do mundo - Walter Benjamin: romantismo e crítica literária. São Paulo: Iluminuras.

VERAS, Viviane (2006) "Freud: tramas e traumas de um contador de casos". Cadernos Unibero de Produção Científica 1, 73-84.

(1999) Linguisterria: um chiste. Tese de doutorado. Instituto de Estudos da Linguagem, Unicamp.

ŽIŽEK, S. (1991) O mais sublime dos histéricos: Hegel com Lacan. Trad. de Vera Ribeiro. Rio de Janeiro: Jorge Zahar. 